\title{
Effects of Educational Intervention on Health-Promoting Lifestyle and Health-Related Life quality of Methamphetamine Users and Their Families: a Randomized Clinical Trial
}

\author{
Afsaneh Ghasemi ${ }^{1}$; Fatemeh Estebsari ${ }^{2}$; Amir Bastaminia ${ }^{3}$; Ensiyeh Jamshidi ${ }^{4}$; Maryam \\ Dastoorpoor $^{5, *}$
}

${ }^{1}$ Department of Health Education and Promotion, School of Public Health, Fasa University of Medical Sciences, Fasa, IR Iran

${ }^{2}$ Department of Health, School of Nursing and Midwifery, Shahid Beheshti University of Medical Sciences, Tehran, IR Iran

3 Department of Geography, School of Humanities, University of Yazd, Yazd, IR Iran

${ }^{4}$ Community Based Participatory Research Center, Iranian Institute for Reduction of High-Risk Behaviors, Tehran University of Medical Sciences, Tehran, IR Iran

5 Research Center for Modeling in Health, Institute for Futures Studies in Health, Kerman University of Medical Sciences, Kerman, IR Iran

${ }^{*}$ Corresponding Author: Maryam Dastoorpoor, Research Center for Modeling in Health, Institute for Futures Studies in Health, Kerman University of Medical Sciences, Kerman, IR Iran. Tel: +98-3413205090, Fax: +98-3413205134, E-mail: mdastoorpour@yahoo.com

Received: May 6, 2014; Revised: September 13, 2014; Accepted: October 8, 2014

\begin{abstract}
Background: Family-centered empowerment of drug and stimulant users is an effective program for a better response to treatment, prevention of treatment adverse effects, and promotion quality of life (QoL) and lifestyle in the process of discontinuing drug abuse. Objectives: This study aimed to determine the effects of educational intervention, based on family-centered empowerment and Pender's health promotion models, on health-promoting lifestyle and health-related QoL among methamphetamine users and their families. Patients and Methods: In a randomized clinical trial, methamphetamine users, who were admitted to Tehran University of Medical Sciences Substance Abuse Treatment Centers, were randomly allocated to three groups: a group for training of methamphetamine users who were in recovery phase (intervention group 1;95 subjects);a group for training of a family member of methamphetamine users who were in recovery phase (intervention group 2; 95 subjects); and a control group (95 subjects). A demographic checklist and a standard questionnaire covering health-promoting lifestyle, health-related QoL, self-efficacy, perceived affect, perceived social support, and perceived barriers dimensions were used to gather required data. Independent-samples $t$ test, paired-samples t-test, and ANCOVA were used to analyze the data.

Results: Analysis of covariance showed that after adjusting for effects of pretest scores, the difference between mean post-test scores of health-promoting lifestyle scale, health-related QoL scale, and all constructs of Pender's health promotion model (self-efficacy, perceived affect, perceived social support, and perceived barriers) in the intervention group 1 and control group were significant $(\mathrm{P}<0.0001)$. In addition, changes in mean scores of lifestyle scale (42.4 \pm 13.6$)$, QoL scale (29.1 \pm 14.2$)$, self-efficacy (16.1 \pm 2.6$)$, perceived affect (16.1 \pm 8$)$, social support (35.4 \pm 12.4$)$, and barriers (17.2 \pm 15.8$)$ before and after intervention were significant in the intervention group $2(\mathrm{P}<0.0001)$.

Conclusions: Application of family-centered empowerment model among methamphetamine users and their families is practically feasible and can result in enhancement and improvement of their QoL, lifestyle, and health promotion model constructs.
\end{abstract}

Keywords:Family Nursing; Life Style; Quality of Life; Health Promotion; Methamphetamine

\section{Background}

Methamphetamine is a central nervous system stimulant, which is produced by synthesis and combination of extremely dangerous chemicals (1). According to United Nations Office on Drugs and Crime (UNODC) report in 2013, Iran holds the fifth rank among the countries with high consumption of methamphetamine (2). Methamphetamine abuse often leads to numerous sequels including serious psychological problems, criminal involvements, matrimonial problems and divorce, emotional and social problems, and job instability. These all demote quality of life (QoL) and lifestyle of methamphetamine users (3). Nonetheless, medical interventions for methamphetamine abuse has received due attention mostly and its psychological tangles such as QoL lack that attention (4). According to World Health Organization, $70 \%$ to $80 \%$ and $40 \%$ to $50 \%$ of mortalities in respectively developed and developing countries emanate from lifestyle-related diseases and habits such as drug abuse (5). Pender defines lifestyle as a pattern of daily living voluntarily activities that seriously affect one's health, which originates from demographic, environmental, and social milieu and context (6). Pender also considers the healthpromoting lifestyle as a multidimensional pattern of self-initiated actions and perceptions that maintains or enhances the level of health, QoL, self-actualization, and self-fulfillment. Therefore, lifestyle is one of the impor-

Copyright ( ) 2014, Iranian Red Crescent Medical Journal. This is an open-access article distributed under the terms of the Creative Commons Attribution-NonCommercial 4.0 International License (http://creativecommons.org/licenses/by-nc/4.0/) which permits copy and redistribute the material just in noncommercial usages, provided the original work is properly cited. 
tant elements in promoting health (7). On the other hand, health-related QoL can provide a comprehensive picture of individuals' health, which can be used in monitoring people's health, determination of health-related needs and priorities, evaluation of interventions effectiveness, and comparison of interventions with each other (8). Given the problems in changing and maintenance of healthpromoting lifestyle and QoL among methamphetamine users, it is necessary to use relevant behavior change theories and patterns along with effective interventions to draw people out of such an addictive trap. One of the most comprehensive and predictive models on healthpromoting lifestyle and health-related QoL is Pender's health promotion model (PHPM), which is considered as a framework to determine health-promoting lifestyle behaviors. PHPM consists of three groups of factors: 1) individual characteristics and experiences; 2) behaviorspecific cognition and affect; and 3 ) behavioral outcomes (9). Behavior-specific cognition and affect factors, which points to most fundamental behavioral motivations, consist of a series of variables including perceived self-efficacy, perceived affect, perceived barrier, and perceived social support that are in the core of empowerment-driven interventions (7). Similar to other drugs, methamphetamine abuse has negative effects on the user and contaminates the family and even the whole society. Therefore, it is necessary to empower methamphetamine user as well as their family members to control the addiction and adopt a healthy lifestyle and better QoL. Most scientists hold that empowerment is a dynamic, positive (10, 11), interactive, and a social process (12) that takes place in the relationship with others and leads to the improvement of QoL and health promotion among the patients and better response to treatment (13). Family-centered empowerment model (FCEM),which emphasizes on individuals and their family members' role, is comprised of three motivational, psychologic, and problem characteristics (14). The main purpose of FCEMis to empower the family system, ie, patient and other family members, to promote health. This model has been used for health promotion among patients with chronic diseases; however, it has not been used for drug and stimulant abuse, especially for methamphetamine abuse. Therefore, given the results of numerous studies on alarming magnitude of methamphetamine use in Iran, a family-centered effective planning with a direct focus on society seems necessary to reduce consumption of drugs and stimulants, especially methamphetamine.

\section{Objectives}

This study aimed to determine the effects of educational intervention based on FCEM and PHP Mon healthpromoting lifestyle and health-related QoL among methamphetamine users, who were admitted to Tehran University of Medical Sciences Substance Abuse Treatment centers, and their families.

\section{Patients and Methods}

\subsection{Study Population and Sampling}

In this randomized clinical trial with an educational intervention and a preintervention/post intervention design, methamphetamine-dependent individuals and their families were recruited. All subjects were in recovery phase and were admitted to Tehran University of Medical Sciences, Tehran, Iran, clinics during a 12-month period from 2012 to 2013. Inclusion criteria were as follows: being between 20 to 64 years old, a history of drug abuse of less than ten years, being in recovery phase, detoxified, and willing to participate in the study. Drug use relapse and unwillingness to participate were the exclusion criteria. Random numbers table was used to select subjects and their family members. Then they were randomly allocated to two intervention and a control groups. Intervention groups comprised of one group of methamphetamine users in recovery ( 95 subjects) and one group of their family members (father, mother, sister, or brother of single patients and wife or child of married ones) (95 subjects).Control group included methamphetamine users in recovery phase who received no educational intervention (95 subjects).

\subsection{Sample Size}

Odds ratio (OR) was used to choose the required sample. A study showed that about $50 \%$ of uneducated methamphetamine users had a low level of QoL (15); indeed, its OR among educated users was 2.5 times as high as OR among uneducated ones. Considering 95\% confidence interval (CI) and 80\% power, the following formula was used to choose the sample.

$$
\begin{aligned}
& \mathrm{p}_{1}=0.5, \mathrm{p}_{2}=\left(\mathrm{p}_{1} \times \mathrm{OR}\right) /\left[1+(\mathrm{OR}-1) \mathrm{p}_{1}\right]=0.7, \mathrm{P}=\left(\mathrm{p}_{1}+\mathrm{p}_{2}\right) / 2 \\
& =0.6, \text { and } 1-\mathrm{P}=0.4 \\
& \mathrm{n}=2\left\{\left(\mathrm{Z}_{1-\alpha / 2}+\mathrm{Z}_{1-\beta}\right)^{2} \times[(\mathrm{P}) \times(1-\mathrm{P})]\right\} /\left(\mathrm{p}_{1}-\mathrm{p}_{2}\right)^{2} \\
& \text { The optimum sample size for each study group was } 95
\end{aligned}
$$
and thus, 285 subjects were recruited. TUMS clinics are somehow evenly distributed in all north, south, west, and east parts of the city and can be representative of willingto-quit methamphetamine abusers in Tehran. Flow chart of RCT for intervention group 1 and controls is shown in Figure 1.

\subsection{Instruments}

Tools used to gather required data were as follows:

1) A demographic checklist on age, sex, level of education, and marital status of subjects.

2) A health-promoting lifestyle profile: this profile was derived from Walker et al. (16) study and included 52 questions in four sections, namely, nutrition, health responsibility, physical activity, and stress management. The questions were designed based on Likert scale with four choices ranging from "never" to "always". Obtained total score ranged from 52 to 208 with higher scores indicating a better health-promoting lifestyle (16). 


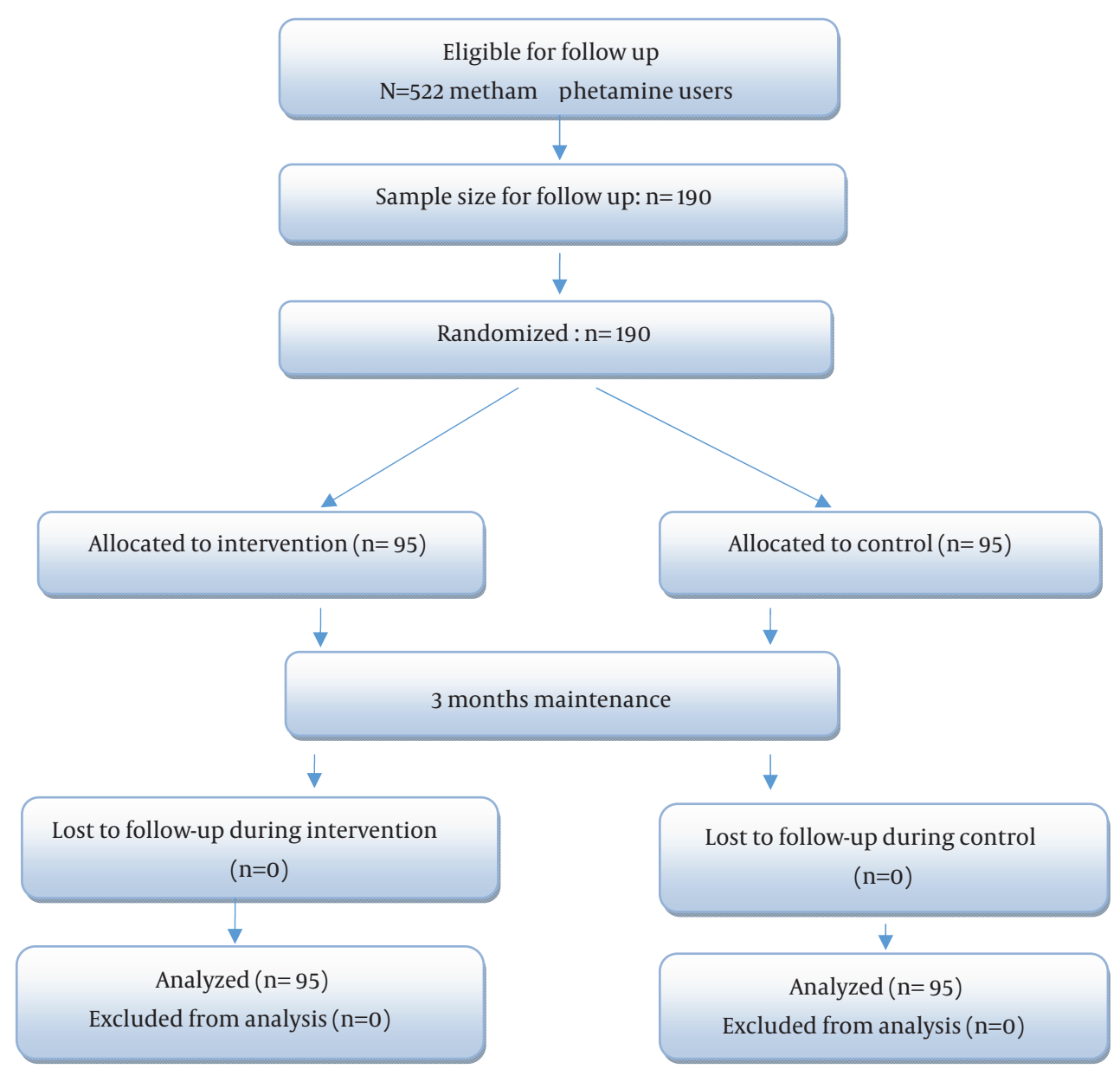

Figure 1. Flow chart of Randomized Clinical Trial

\subsection{Health-Related Quality of Life Scale}

To measure health-related QoL, SF-36 (Short Form 36) QoL questionnaire, validity and reliability of which had been confirmed in Iran, was used (17). This questionnaire includes 36 questions in eight dimensions: physical functioning, role limitations due to physical health, role limitations due to emotional problems, energy/fatigue, mental wellbeing, social functioning, pain, and general health. This questionnaire is designed in a five-choice Likert scale, with scores ranging from one to five. For the scoring purpose, raw scores of each section are calculated and summed together and then are converted to standard scores. Standardized score for each dimension of QoL ranges from zero to 100. The higher scores indicate a better health-related QoL.

\subsection{Information Pertaining Pender's Health-Pro- motion Model}

Information pertaining PHPM included following questionnaires:

\subsubsection{Perceived Self-Efficacy}

This questionnaire was obtained from Smith et al. health scale, which included ten questions in eight sections: achieving health, not achieving to optimal health, difficulty in finding the solution, succeeding in health plans, achieving the aims, attempts for achieving health, believing that plans do not work, and believing that plans work. The answers were in a five-choice Likert scale ranging from "strongly agree" to "strongly disagree", with total score ranging from eight to 40 . The higher the obtained score, the higher the ability of the individual to control the results and effects of their health-related plans (18).

\subsubsection{Perceived Affect}

This questionnaire was obtained from Watson et al. (19) devised tool and included 20 questions in six sections: creative, enthusiastic, interested, nervous, guilty, and strong. Each question was rated in a five-choice Likert scale ranging from "not at all" to "absolutely", with total 
score ranging from 20 to 100 . The higher score showed that the individual had better emotional feelings over the past 24 hours (19).

\subsubsection{Perceived Social Support}

This questionnaire was obtained from Canty-Mitchell and Zimet (20) study and included 12 questions in three sections: family support, friends support, and specific individual support. The answers were rated in a five-choice Likert scale ranging from "strongly agree" to "strongly disagree". The total obtained score ranges from 12 to 60 . The higher scores indicated getting more support from friends, family, and other important individuals (20).

\subsubsection{Perceived Barrier}

This questionnaire was obtained from Becker et al. (21) scale and included 18 questions in six sections: lack of facilities, physical problems, disinterestedness, lack of support, lack of information, and lack of time. These items were rated in a four-choice Likert scale ranging from "never" to "always". The total scores ranged from 18 to 72 . The higher score showed that the responder encountered more barriers to conduct health-promoting behaviors (21). The Farsi versions of all these questionnaires, i.e. health-promoting lifestyle, health-related QoL, perceived self-efficacy, perceived affect, perceived social support, perceived barrier, with the reported Cronbach's alpha coefficient of $0.90,0.77,0.71,0.74,0.73$, and 0.72 , respectively) were used in this study. Validity and reliability of all tools were confirmed in Iran (7). Content validity index (CVI) and content validity ratio (CVR) were determined and confirmed by a panel of experts $(n=10)$ who reviewed scaled items (7).

\subsection{Intervention Program}

The main purpose of the intervention was to improve social support, health (physical, mental, and perceived social support), and QoL among methamphetamine addicts and their families. Enhancement of social and psychoanalytic function, improvement of self-confidence and knowledge about the problems, prevention from disease reoccurrence, empowerment against stressful situations, and recognition of important supportive sources such as family members and other significant others were other aims of this study. The general principles of the intervention were as follows: acknowledgment, assurance, empathy, encouragement, and provision of chance to express emotions in order to obtain social support from others.

The intervention program was conducted in nine sessions as follows: 1) introduction of group members, statement of treatment purpose, definition of drugs, and methods of prevention; 2) definition of QoL and its dimensions; 3 ) emphasis on identification of supportive resources and optimal usage of these resources in addiction treatment; 4 ) training on problem solving methods in order to encounter life in a sustain manner and identification of opportunities to express emotions to identified members of social support resources; 5) training relief techniques and positive visualization to reduce anxiety and enhance internal tranquility; 6) analysis of the sense of sin and alleviation of it and seize of chances to express emotions to group members; 7) training on methods of self-confidence and self-esteem reinforcement based on personal abilities and applying them to deal with daily activities; and 8) statement of summary of last sessions topics and giving feedback.

\subsection{Ethical Considerations}

Ethical issues including plagiarism, informed consent, misconduct, data fabrication and/or falsification, double publication and/or submission, and redundancy were completely observed and considered by the authors. The Ethics Committee of Tehran University of Medical Sciences approved the study protocol (code No:17090; date: February 4, 2012). For ethical reasons, control group was also educated at the end of the study.

\subsection{Statistical Analysis}

Normality of gathered data was tested and confirmed by Kolmogorov-Smirnov test. Chi-square test; independent-samples t-test, paired-samples $t$ test, and analysis of covariance (ANCOVA) were used to analyze the data

\section{Results}

The mean age of methamphetamine users during drug withdrawal and their family members were $23.2 \pm 12.8$ and $31.1 \pm 8.2$, respectively. Most of the methamphetamine users (69.5\%) were 15 to 34 years old, male (75.3\%), and with no academic education (63.7\%). Table 1 illustrates the characteristics of subjects. Independent-samples t-test and Chi-square test for homogeneity of demographic variables (age, $\mathrm{P}=0.89$; sex, $\mathrm{P}=0.06$; and education level, $\mathrm{P}=0.70$ ) before educational intervention in the intervention groups 1 and control group, did not show any significant statistical association. Independent-samples t-test also showed that preintervention mean scores of healthrelated QoL scale and PHPM constructs (perceived affect, perceived social support, and perceived barriers) were not significant in the intervention group 1 and control group $(P>0.05)$; however, these parameters were significant for health-promoting lifestyle scale and self-efficacy indicators $(\mathrm{P}<0.05)$ (Table 2$)$.

To adjust for the effects of pretest on the post-test results, a covariance analysis was used. Consequently, differences between mean scores of post-test health-related QoL, self-efficacy, perceived affect, perceived social support, and perceived barriers in the intervention group1 and control were statistically significant $(P<0.0001)$ (Table 3). In other words, it seems that in the intervention group 1, the educational intervention effectively worked towards generation and promotion of health-promoting 
lifestyle, health-related QoL, and all constructs of PHPM (self-efficacy, perceived affect, perceived social support, and perceived barriers). Interestingly enough, preintervention and post intervention paired-samples t-test showed that the mean scores of health-promoting lifestyle scale, health-related QoL scale, and all constructs of PHPM (self-efficacy, perceived affect, perceived social sup- port, and perceived barriers) were also significant in the intervention group 2 (P value $<0.0001$ ) (Table 4 ). In other words, it seems that educational intervention had positive effect on health-promoting lifestyle, health-related QoL, self-efficacy, perceived affect, perceived social support, and perceived barriers in the intervention group 2 .

\begin{tabular}{lccc}
\hline \multicolumn{1}{l}{ Table 1. Distribution of Demographic Variables Among Study Groups ${ }^{\mathrm{a}}$} & & \\
\hline Variables & Intervention Group 1 & Intervention Group 2 & Control Group \\
\hline Age, $\mathbf{y}$ & $32.8 \pm 7.9$ & $23.2 \pm 12.8$ & $29.3 \pm 8.3$ \\
$\mathbf{S e x}$ & & & $77(81.1)$ \\
$\quad$ Male & $66(69.5)$ & $37(38.9)$ & $18(18.9)$ \\
$\quad$ Female & $29(30.5)$ & $58(61.1)$ & $61(64.2)$ \\
Educational level & & & $16(16.8)$ \\
$\quad$ Non-academic & $60(63.2)$ & $8(8.4)$ & $18(18.9)$ \\
\hline
\end{tabular}

a Data are presented as Mean \pm SD or No. (\%).

\begin{tabular}{lcccc}
\hline Table 2. Mean Scores of Quality of Life Indicators in the Intervention 1 and Control Groups Before Educational Intervention ${ }^{\text {a, b }}$ \\
\hline Indicators & Intervention Group 1 & Control Group & t & PValue \\
\hline Health-promoting lifestyle & $99.7 \pm 20$ & $109 \pm 26.1$ & -2.8 & 0.006 \\
Health-related quality of life & $55.8 \pm 15.2$ & $54 \pm 14.3$ & 0.8 & 0.4 \\
Self-efficacy & $19.6 \pm 2.9$ & $20.8 \pm 2.1$ & -3.1 & 0.002 \\
Perceived affect & $54 \pm 9.4$ & $52.1 \pm 11.6$ & 1.2 & 0.2 \\
Perceived social support & $37.4 \pm 17.7$ & $36.1 \pm 15.1$ & 0.5 & 0.6 \\
Perceived barriers & $47.6 \pm 5.9$ & $46.8 \pm 3.7$ & 1.1 & 0.3 \\
\hline
\end{tabular}

${ }^{\mathrm{a}}$ Data are presented as Mean \pm SD.

$\mathrm{b}_{\text {t-statics }}$

\begin{tabular}{|c|c|c|c|c|}
\hline Indicators & df & Mean Square & $\mathbf{F}^{\mathrm{a}}$ & P Value \\
\hline \multicolumn{5}{|c|}{ Health-promoting lifestyle } \\
\hline Pretest & 1 & 69199 & 685.1 & $<0.0001$ \\
\hline Group & 1 & 138271.8 & 1369 & $<0.0001$ \\
\hline \multicolumn{5}{|c|}{ Health-related quality of life } \\
\hline Pretest & 1 & 10249.5 & 133.3 & $<0.0001$ \\
\hline Group & 1 & 40891 & 531.9 & $<0.0001$ \\
\hline \multicolumn{5}{|l|}{ Self-efficacy } \\
\hline Pretest & 1 & 7.4 & 1.05 & 0.31 \\
\hline Group & 1 & 5425.6 & 766.8 & $<0.0001$ \\
\hline \multicolumn{5}{|c|}{ Perceived affect } \\
\hline Pretest & 1 & 11522 & 458 & $<0.0001$ \\
\hline Group & 1 & 7159 & 284.5 & $<0.0001$ \\
\hline \multicolumn{5}{|c|}{ Perceived social support } \\
\hline Pretest & 1 & 33134.7 & 463.9 & $<0.0001$ \\
\hline Group & 1 & 17029.3 & 238.4 & $<0.0001$ \\
\hline \multicolumn{5}{|c|}{ Perceived barriers } \\
\hline Pretest & 1 & 430.2 & 21.4 & $<0.0001$ \\
\hline Group & 1 & 23731.5 & 1178 & $<0.0001$ \\
\hline
\end{tabular}

\footnotetext{
${ }^{a}$ F-statistics.
} 
Ghasemi A et al.

Table 4. Mean Scores of on Quality of life indicators in Member of Methamphetamine Users Family Before and After the Educational Intervention ${ }^{\mathrm{a}}$

\begin{tabular}{lccc}
\hline Variables & Before Intervention & After Intervention & PValue \\
\hline Health-Promoting Lifestyle & $122.2 \pm 25.7$ & $164.6 \pm 20.2$ & $<0.0001$ \\
Health-Related Quality of Life & $63.9 \pm 16.6$ & $93 \pm 4$ & $<0.0001$ \\
Self-Efficacy & $19 \pm 2.9$ & $35.2 \pm 1.9$ & $<0.0001$ \\
Perceived Affect & $58.1 \pm 7.4$ & $74.2 \pm 5.3$ & $<0.0001$ \\
Perceived Social support & $40 \pm 14.5$ & $75.4 \pm 7.2$ & $<0.0001$ \\
Perceived Barriers & $44.1 \pm 8.5$ & $26.9 \pm 8$ & $<0.0001$ \\
\hline
\end{tabular}

${ }^{\mathrm{a}}$ Data are presented as mean $\pm \mathrm{SD}$.

\section{Discussion}

Effective interventions based on health promotion models are considered as solutions for public health problems. The present study aimed to investigate the effects of an educational program, based on FCEM, on health-promoting lifestyle, health-related QoL, and constructs of PHPM among methamphetamine abusers and their family members. Results showed that among methamphetamine users and their family members, performed educational program, based on FCEM that focuses on supportive psychotherapy, effectively worked towards total health-promoting lifestyle, total healthrelated QoL, and constructs of PHPM. In other words, educational intervention was acceptable and desirable for methamphetamine users and their family members. Individuals under the aegis of FCEM were taught on following issues: problem solving methods that help better deal with life issues; identification of opportunities for catharsis; relaxation and positive imagination to reduce stress and create internal calmness; investigation of reasons for feeling guilty and ways to tackle it; methods to increasing self-confidence with reliance on personal abilities; and encouragement to do useful daily tasks. These all led to considerable improvement in subjects' lifestyle, QoL, and perceived-cognitive factors. Comparing to preintervention scores, post intervention average score of health-promoting lifestyle scale among groups under the educational intervention was statistically significant. Healthy lifestyle literally means a kind of balance in life so that one can make wise choices through life. According to recent studies, a healthy lifestyle includes the following components: a sense of security, a risk-free life, participation in voluntarily social activities, and perception and recognition of risks (22). Post intervention average score of perceived social support, including support from parents, relatives, and friends, was significant among intervention groups. This finding was in line with Heidari et al. study who investigated the effect of supportive psychotherapy sessions on permanent drug withdrawal (23). It was also in line with Knowlton et al. study who investigated the positive effect of social support behaviors of drug injectors (24). Social support is considered as an important factor in the process that stops drug abuse. A study conducted in the United States among methamphetamine users showed that they related committing suicide to inappropriate relations between parents and children, lack of support from family, and improper social relations at school and in society (25). This indicated that if an individual receives proper social support, they would be more likely to learn and use encountering skills such as problem solving, social skills, and communicational skills and would try to make these skills more effective. Indeed, their health becomes more important for them and consequently, provided treatment and care works better in preventing them from drug abuse recurrence in high-risk situations (26). Our findings revealed that post intervention average score of health-related QoL among intervention groups was significantly higher than controls, which was in line with Hosseinian et al. study (27). In fact, this vulnerable group needs supportive and psychologic education to enjoy a high quality and healthy life. This type of education is also expected to reduce their physical and mental problems. our results showed that post intervention average score of total self-efficacy among intervention groups was significantly higher than controls, which was in line with the study of Rounds-Bryant et al. on tobacco and alcohol misuse treatment (28). In another research on selfefficacy and addiction, it was shown that high self-efficacy would reduce the risk of methamphetamine and alcohol use (29). One of the effective ways to increase self-efficacy among addicts is to provide a proper education for those who are highly exposed to risks and create opportunities for them to observe others peoples' success. These might create a context for self-efficacy and consequently, might minimize depression symptoms. Moreover, they can be used as tools to avoid drug use after withdrawal (30). Difficulty in recognition of positive excitements and insufficiency in establishment of emotional relationships with others are of main characteristics of drug abusers (31). The ability to perceive emotions can make individuals resistant and secure when encountering momentums and challenges. In present study, post intervention aver- 
age score of perceived emotions among intervention groups was also significantly higher than controls. Studies have revealed that with growth of positive emotions and excitements, communicational skills also improve and individuals get determined to stop addiction $(31,32)$. This study showed that post intervention average score of perceived barriers for intervention groups was significantly higher in comparison to preintervention scores. Barriers are often considered as obstacles or personal expenses resulting from a particular behavior. Concerning methamphetamine use, overcoming perceived barriers requires an attempt to change improper beliefs about methamphetamine as well as inappropriate and incompatible purposes, and to make wise decisions to stop methamphetamine addiction. To realize that, methamphetamine users need special consultation, medical treatment for addiction symptoms, and special centers equipped sufficiently for methamphetamine treatment. One of the strength points of this study is that it was a randomized clinical trial, which doubles its worth in comparison to other similar descriptive studies. However, those addicts who entered the study and experienced methamphetamine abuse for the first time were not able to answer questions correctly and this could cloud the results. In addition, although the present study tried to consider cultural diversity, such a consideration defies to be fully done and it should be considered when interpreting the results. Administration of FCEM among methamphetamine users and their family members is practically feasible and results in enhancement and improvement of their QoL and lifestyle. Therefore, family-centered empowerment approach can be used in future interventions to improve lifestyle and QoL of other vulnerable groups and their family members.

\section{Acknowledgements}

This study was part of a PhD thesis conducted at Tehran University of Medical Sciences. The authors would like to thank the participants in the study.

\section{Authors' Contributions}

All authors had participated in different parts of study.

\section{Funding/Support}

This study was funded and supported by Tehran University of Medical Sciences, Tehran, Iran (Grant No.17090).

\section{References}

1. Newton TF, De La Garza R, 2nd, Kalechstein AD, Tziortzis D, Jacobsen CA. Theories of addiction: methamphetamine users explanations for continuing drug use and relapse. Am J Addict. 2009;18(4):294-300.

2. United Nations Office on Drugs and Crime. World drug report. United Nations Publications. 2010.

3. Russell K, Dryden DM, Liang Y, Friesen C, O'Gorman K, Durec T, et al. Risk factors for methamphetamine use in youth: a systematic review. BMC Pediatr. 2008;8:48.
4. World Health Organization. QOL-BREF introduction administration scoring and generic version of the assessment field trial version. Geneva:WHO. 1996.

5. Kaplan NM. Hypertension curriculum review: lifestyle modifications for prevention and treatment of hypertension. J Clin Hypertens (Greenwich). 2004;6(12):716-9.

6. Al-Kandari F, Vidal VL. Correlation of the health-promoting lifestyle, enrollment level, and academic performance of College of Nursing students in Kuwait. Nurs Health Sci. 2007;9(2):112-9.

7. Mohamadian H, Eftekhar H, Rahimi A, Mohamad HT, Shojaiezade D, Montazeri A. Predicting health-related quality of life by using a health promotion model among Iranian adolescent girls: a structural equation modeling approach. Nurs Health Sci. 2011;13(2):141-8.

8. Muller Nordhorn J. Assessing quality of life in clinical trials. J Epidemiol Community Health. 2006;60(9):822.

9. Pender NJ, Murdaugh CL, Parsons MA. The health promotion model. Health Prom Nurs Prac. 2002;4.

10. Mok E, Martinson I, Wong TK. Individual empowerment among Chinese cancer patients in Hong Kong. West J Nurs Res. 2004;26(1):59-75.

11. Arvidsson SB, Petersson A, Nilsson I, Andersson B, Arvidsson BI Petersson IF, et al. A nurse-led rheumatology clinic's impact on empowering patients with rheumatoid arthritis: A qualitative study. Nurs Health Sci. 2006;8(3):133-9.

12. Holmstrom I, Roing M. The relation between patient-centeredness and patient empowerment: a discussion on concepts. $\mathrm{Pa}$ tient Educ Couns. 2010;79(2):167-72.

13. Chavasse JM. New Dimensions of Empowerment in Nursing ? And Challenges. J Adv Nurs.1992;17(1):1-2.

14. Vahedian Azimi A, Alhani F, Ahmadi F, Kazemnejad A. Effect of family-centered empowerment model on the life style of myocardial infarction patients. Iran J Crit Care Nurs. 2010;2(4):127-32.

15. Gonzales R, Ang A, Marinelli-Casey P, Glik DC, Iguchi MY, Rawson RA, et al. Health-related quality of life trajectories of methamphetamine-dependent individuals as a function of treatment completion and continued care over a 1-year period. $J$ Subst Abuse Treat. 2009;37(4):353-61.

16. Walker SN, Sechrist KR, Pender NJ. The health-promoting lifestyle profile II. Nurs Res. 1995.

17. Montazeri A, Goshtasebi A, Vahdaninia M, Gandek B. The Short Form Health Survey (SF-36): translation and validation study of the Iranian version. Qual Life Res. 2005;14(3):875-82.

18. Smith MS, Wallston KA, Smith CA. The development and validation of the Perceived Health Competence Scale. Health Educ Res. 1995;10(1):51-64.

19. Watson D, Clark LA, Tellegen A. Development and validation of brief measures of positive and negative affect: the PANAS scales. J Pers Soc Psychol.1988;54(6):1063-70.

20. Canty-Mitchell J, Zimet GD. Psychometric properties of the Multidimensional Scale of Perceived Social Support in urban adolescents. Am J Community Psychol. 2000;28(3):391-400.

21. Becker H, Stuifbergen A. What makes it so hard? Barriers to health promotion experienced by people with multiple sclerosis and polio. Fam Community Health. 2004;27(1):75-85.

22. Arria AM, Derauf C, Lagasse LL, Grant P, Shah R, Smith L, et al Methamphetamine and other substance use during pregnancy: preliminary estimates from the Infant Development, Environment, and Lifestyle (IDEAL) study. Matern Child Health J. 2006;10(3):293-302.

23. Heidari H, Beiranvnd N. Comparison of causes of drug abuse from the viewpoint of addicted patients and their families. Health Syst Res. 2012;8(6):1017-26.

24. Knowlton A, Hua W, Latkin C. Social support among HIV positive injection drug users: implications to integrated intervention for HIV positives. AIDS Behav. 2004;8(4):357-63.

25. McLellan AT, Grissom GR, Zanis D, Randall M, Brill P, O'Brien CP. Problem-service 'matching' in addiction treatment. A prospective study in 4 programs. Arch Gen Psychiatry. 1997;54(8):730-5.

26. Stephens RS, Roffman RA, Curtin L. Comparison of extended versus brief treatments for marijuana use.J Consult Clin Psychol. 2000;68(5):898-908 


\section{Ghasemi A et al.}

27. Hosseinian S, Tabatabaei S, Ravaei F. Effectiveness of Supportive Psychotherapy on Quality of Life of Women with HIV in Kermanshah. Procedia Soc Behav Sci. 2011;30:1902-7.

28. Rounds-Bryant JL, Flynn PM, Craighead LW. Relationship between self-efficacy perceptions and in-treatment drug use among regular cocaine users. Am J Drug Alcohol Abuse. 1997;23(3):383-95.

29. Halkitis PN, Parsons JT, Stirratt MJ. A double epidemic: crystal methamphetamine drug use in relation to HIV transmission among gay men. J Homosex. 2001;41(2):17-35.
30. McKellar J, Ilgen M, Moos BS, Moos R. Predictors of changes in alcohol-related self-efficacy over 16 years. J Subst Abuse Treat. 2008;35(2):148-55.

31. Parker JDA, Taylor GJ, Bagby RM. The relationship between emotional intelligence and alexithymia. Pers Individ Dif. 2001;30(1):107-15.

32. Parker JD, Taylor RN, Eastabrook JM, Schell SL, Wood LM. Problem gambling in adolescence: Relationships with internet misuse, gaming abuse and emotional intelligence. Personality and Individual Differences. 2008;45(2):174-80. 